\title{
Balloon atrial septostomy for total anomalous pulmonary venous return ${ }^{\mathrm{I}}$
}

\author{
Charles E. Mullins, Galal M. El-Said, William H. Neches, Robert L. Williams,
} Thomas A. Vargo, Michael R. Nihill, and Dan G. McNamara

From The Section of Cardiology, Department of Pediatrics, Baylor College of Medicine; and Texas Children's Hospital, Houston, Texas, U.S.A.

During the 2-year period fuly 1970 to fuly 1972, balloon atrial septostomy was performed in 12 patients with total anomalous pulmonary venous return, ranging in age from 4 days to $I$ year, and in weight from 2.27 to $6.80 \mathrm{~kg}$. After septostomy, 9 of the 12 patients were improved both clinically and haemodynamically. Of these 9 patients, I died inexplicably $I$ week after the septostomy. In the remaining 8 patients, improvement was maintained during follow-up ranging from 7 months to 2 years. Repeat cardiac catheterization in 4 patients documented continued haemodynamic improvement.

Of the I2 patients, 3 were not helped by the septostomy and required operation within a few days. In 2 of these infants, the opening created by the septostomy was found at operation to be too small to have been considered beneficial, yet both of these patients had had less than a I $\mathrm{mmHg}$ mean atrial pressure gradient before septostomy. The third patient, who had infradiaphragmatic return, had a large interatrial communication confirmed at operation.

Based on the results achieved in these patients, balloon atrial septostomy is now recommended at the time of the initial cardiac catheterization in all infants with total anomalous pulmonary venous return. The procedure is less likely to be successful in infants over 3 months of age, and in those with infradiaphragmatic pulmonary venous return. The haemodynamic improvement obtained by successful septostomy in the young infant should allow delay of operation until a more optimal age.

The potential value of balloon atrial septostomy for infants with total anomalous pulmonary venous return, described by Miller et al. (1967) and by Serrato et al. (1968), has been questioned because of the frequent lack of significant interatrial pressure gradient (Leachman et al., 1969; Gathman and Nadas, 1970). The presence of only a small foramen ovale discovered at necropsy in an infant who shortly before her death was denied balloon atrial septostomy on the basis of equal atrial pressures led the authors to the use of the balloon catheter for all infants with total anomalous pulmonary venous return, both to assess the size of the atrial communication and to perform balloon atrial septostomy when feasible. This report discusses the results of the use of the balloon catheter in patients with total anomalous pulmonary venous return over a 2-year period.

Received 29 December 1972.

1 Supported in part by a grant from the National Institutes of Health, United States Public Health Service, and by a USPH grant from the General Clinical Research Branch, National Institutes of Health.

\section{Subjects and methods}

Over the 2-year period July 1970 to July 1972 , balloon atrial septostomy was performed in 12 of the 20 patients with total anomalous pulmonary venous return who underwent cardiac catheterization at Texas Children's Hospital (Table). Balloon atrial septostomy was felt to be inadvisable in the other 8 of the 20 patients with total anomalous pulmonary venous return. Of the 8,5 were over I year of age, I had infradiaphragmatic return, and 2 had large atrial communications as determined by unobstructed withdrawal of a fully inflated balloon across the atrial septum. Of the I2 patients, 2 (Cases I and 2) who had balloon atrial septostomies were described in a previous report (El-Said, Mullins, and McNamara, 1972).

The diagnosis of total anomalous pulmonary venous return was confirmed by selective angiography in each patient. During each catheterization, effort was made to enter the left atrium, left ventricle, common anomalous pulmonary venous channel, right atrium, right ventricle, pulmonary artery, and pulmonary artery wedge position. Entry into each of these sites enabled documentation of any pressure gradient between the left and right atrium, between the anomalous pulmonary venous, channel and 
TABLE Summary of data from patients who underwent balloon atrial septostomy

\begin{tabular}{|c|c|c|c|c|c|c|}
\hline $\begin{array}{l}\text { Case } \\
\text { No. }\end{array}$ & Age and & $\operatorname{sex}$ & $\begin{array}{l}\text { Weight } \\
(k g)\end{array}$ & Type of return & $\begin{array}{l}\text { Pulmonary venous } \\
\text { obstruction }\end{array}$ & $\begin{array}{l}\text { Follow-up period } \\
\text { (to fuly 1972) }\end{array}$ \\
\hline 2 & I mth & $\mathbf{M}$ & $3 \cdot 0$ & Coronary sinus & Mild & $2 \mathrm{yr}$ \\
\hline 3 & I mth & $\mathbf{F}$ & $3 \cdot 8$ & Coronary sinus & Absent & I yr \\
\hline 4 & $35 \mathrm{dy}$ & $\mathbf{M}$ & $5 \cdot 0$ & Vertical vein & Absent & Died suddenly after I wk \\
\hline 5 & I mth & $\mathbf{M}$ & $5 \cdot 4$ & Coronary sinus & Absent & I4 mth \\
\hline 6 & Io mth & $\mathbf{M}$ & 6.6 & Vertical vein & Mild & $14 \mathrm{mth}$ \\
\hline 7 & $7 \mathrm{mth}$ & $\mathbf{F}$ & $5 \cdot 4$ & Vertical vein & Mild & $5 \mathrm{mth}$ \\
\hline 8 & I2 mth & $\mathbf{M}$ & $5 \cdot 9$ & $\begin{array}{l}\text { Right lung: right superior vena cava } \\
\text { Left lung: vertical vein }\end{array}$ & Moderate & $22 \mathrm{mth}$ \\
\hline 9 & I 2 mth & $\mathbf{M}$ & $6 \cdot 7$ & $\begin{array}{l}\text { Left upper lobe: vertical vein } \\
\text { Others: coronary sinus }\end{array}$ & Mild & Operation after I I $\mathrm{mth}$ \\
\hline Io & $4 \mathrm{dy}$ & $\mathbf{F}$ & $3 \cdot 0$ & Right superior vena cava & Absent & Operation after $2 \mathrm{mth}$ \\
\hline I I & $8 \mathrm{dy}$ & $\mathbf{M}$ & $2 \cdot 3$ & Infradiaphragmatic & Severe & Operation shortly after \\
\hline
\end{tabular}

* Note: Cases I to 9 improved after septostomy; Cases 10 to 12 did not improve.

the right atrium, or between the pulmonary artery wedge position and the right atrium. Both phasic and mean pressures were recorded from each location. In order to visualize any areas of pulmonary venous obstruction, large film selective angiocardiography or $35 \mathrm{~mm}$ cineangiography was used, with separate injections, when permissible, into the right and left pulmonary arteries. In some patients, injections were made directly into the common anomalous pulmonary venous channel. The criteria for pulmonary venous obstruction included one or more of the following: (I) pulmonary artery wedge mean pressure Io $\mathrm{mmHg}$ higher than right atrial mean pressure, (2) mean pressure in the common pulmonary venous trunk at least $10 \mathrm{~mm}$ higher than right atrial mean pressure, (3) angiocardiographic evidence of discrete localized obstruction with delayed emptying in the pulmonary venous channels, and (4) infradiaphragmatic return to ductus venosus or to portal vein.

The balloon atrial septostomy was performed using the technique of Rashkind and Miller (1966) originally described for patients with transposition of the great arteries. In patients with total anomalous pulmonary venous return, the usual methods of identifying the left atrial position of the balloon catheter by either (I) entering pulmonary veins, (2) recording a significantly higher left than right atrial pressure, or (3) recording a higher left atrial oxygen saturation are all invalid. In total anomalous pulmonary venous return, the catheter location in the left atrium can only be positively identified by the injection through a double lumen catheter of a small amount of contrast under fluoroscopic visualization. Balloon withdrawal across the septum was performed promptly after balloon inflation to avoid prolonged obstruction of the foramen ovale and, thus, total venous return to the left side of the heart.

After balloon atrial septostomy, systemic and pulmonary arterial oxygen saturations and pressures were remeasured. If both haemodynamic and clinical

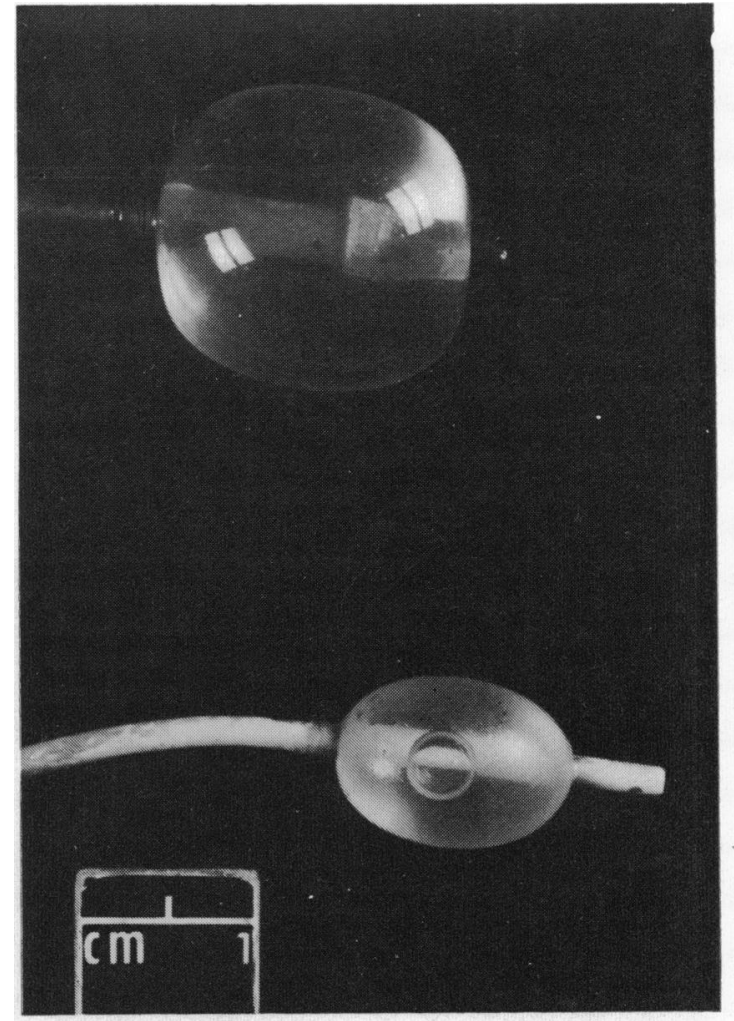

FIG. I (Upper) The size of an inflated balloon which passed easily across the atrial septum after balloon atrial septostomy. (Lower) The size of an inflated balloon which could not be pulled across the atrial septum before balloon atrial septostomy. 

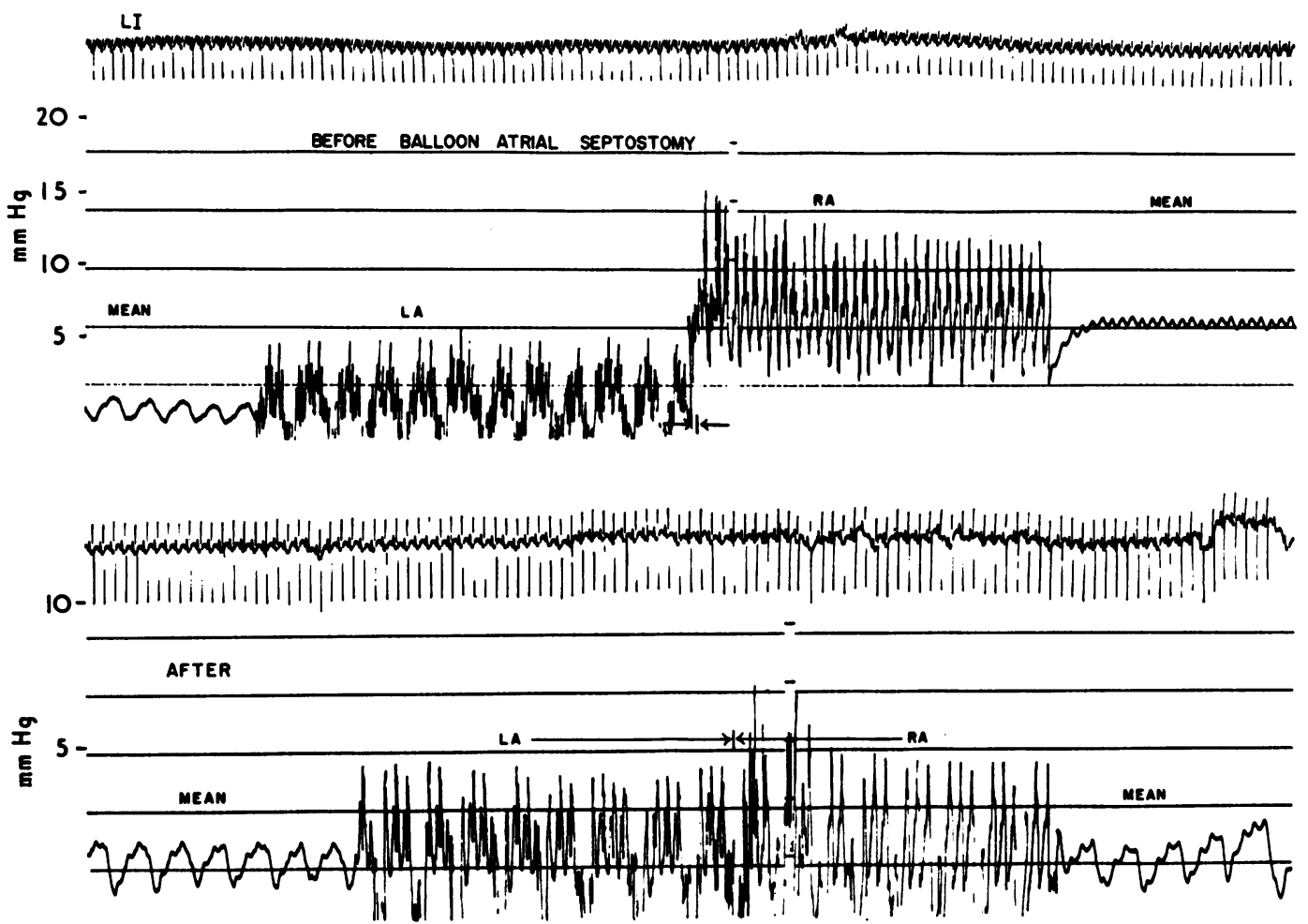

FIG. 2 Withdrawal pressure tracing from the left to the right atrium before (upper) and immediately after (lower) balloon atrial septostomy, showing the disappearance of the gradient between the two atria.

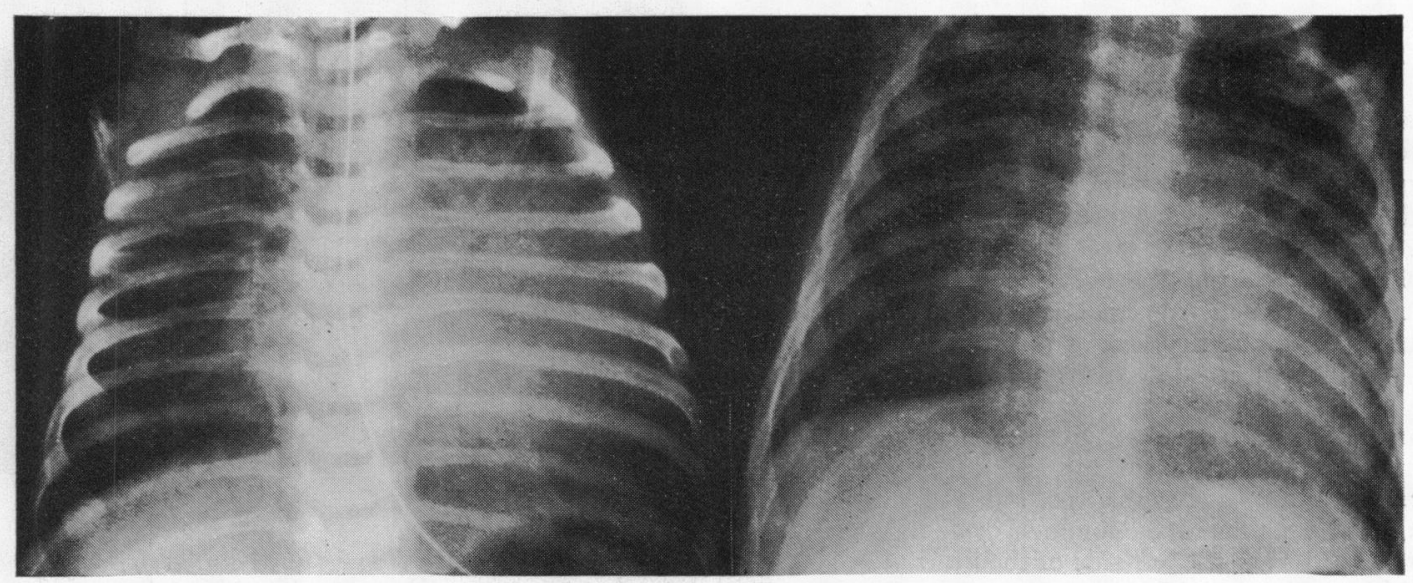

FIG. $3 P A$ x-rays, before (left) and shortly after (right) the atrial septostomy, showing rapid decrease of the heart size and lung vascular markings. 
improvement were evident, the patients were discharged to be followed for variable periods of time until they reached a suitable age and weight for elective total surgical correction. If significant clinical improvement was not initially evident or maintained, surgical correction was attempted shortly after the cardiac catheterization.

\section{Results}

Atrial septostomy was performed without complication in the 12 patients (Fig. I and 2). After balloon atrial septostomy, 9 of the I2 patients (Cases I to 9) were improved clinically, as evidenced by an improvement or alleviation of pulmonary oedema and a decrease in cardiac enlargement (Fig. 3). In the 9 patients who improved clinically, the systolic pulmonary artery and mean right atrial pressures, as well as mean right to mean left atrial pressure gradient, had each decreased significantly (Fig. 4). There was no change in systolic systemic or mean left atrial pressures. Of these 9 patients, I died in-

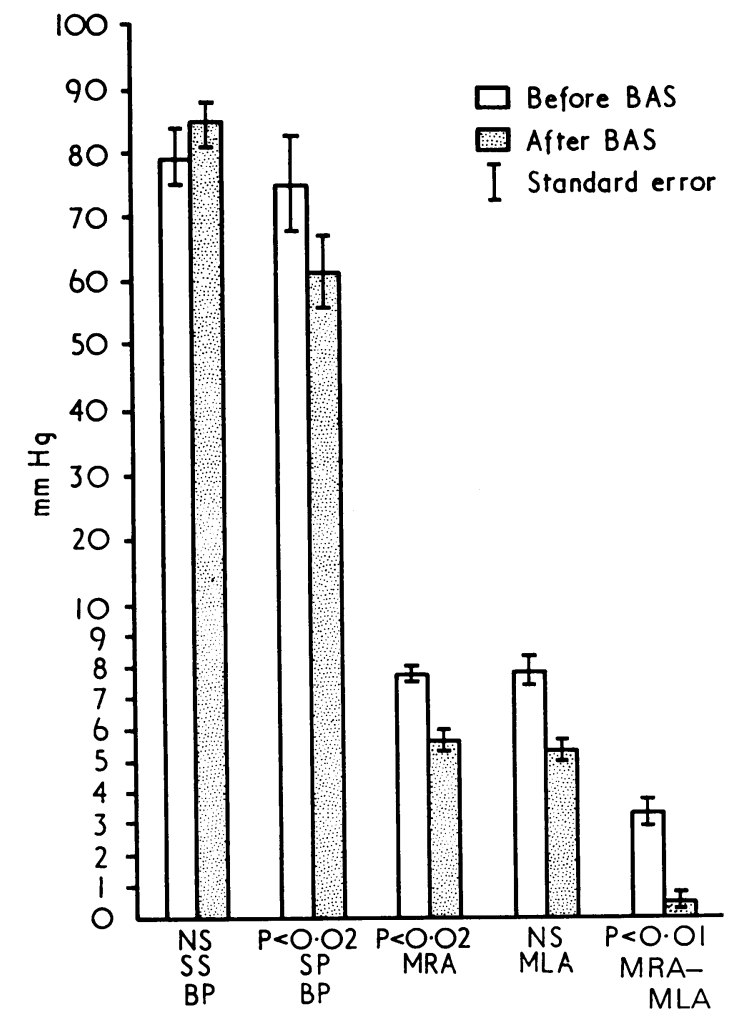

FIG. 4 The mean and standard error of the systolic systemic blood pressure (SSBP), systolic pulmonary blood pressure (SPBP), mean right atrial (MRA), mean left atrial (MLA), and MRA-MLA before and immediately after balloon atrial septostomy (BAS) in the 9 patients who showed definite clinical improvement.
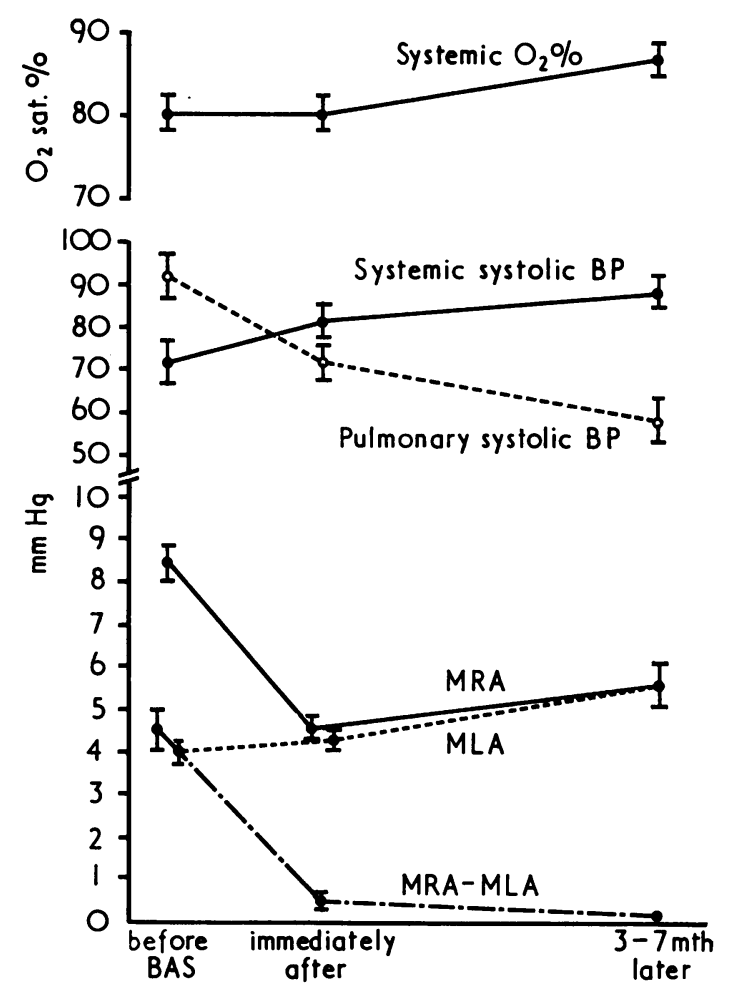

FIG. 5 The mean and standard error of the systemic oxygen saturation, systemic systolic blood pressure, pulmonary systolic blood pressure, right atrial mean $(M R A)$, mean left atrial $(M L A)$, and mean right atrial to mean left atrial pressure gradient (MRA$M L A)$ before and immediately after balloon atrial septostomy, as well as 3 to 17 months later in 4 patients.

explicably I week after septostomy. In the other 8 patients, improvement was maintained during observation periods ranging from 7 months to 2 years. Repeat cardiac catheterization in 4 patients indicated further haemodynamic improvement (Fig. 5).

Of the 12 patients, 3 (Cases Io to 12) were unimproved by the septostomy and required operation within a few days. In 2 of these infants, the opening created by the septostomy was found at the time of operation to be too small to have been beneficial, though both patients had less than a $\mathrm{I} \mathrm{mmHg}$ mean atrial gradient both before and after septostomy. The third patient had a large interatrial communication confirmed at operation but had infradiaphragmatic return.

\section{Discussion}

The condition of total anomalous pulmonary venous return, is actually a group of anomalies with different 
anatomical and haemodynamic types, most of which can be corrected surgically with structural and functional cure. The timing of the operation remains the important question considering the high natural mortality in the untreated infant and the high surgical risk in this age group (Mustard, Keith, and Trusler, I962; Cooley, Hallman, and Leachman, I966; Leachman et al., 1969; El-Said et al., 1972). Using profound hypothermia and total circulatory arrest, Barratt-Boyes, Simpson, and Neutze (197I) and Dillard, Mohri, and Merendino (I97I) reported the successful surgical correction of several infants with total anomalous pulmonary venous return. Gersony et al. (I97I) also reported the successful correction of infants with total anomalous pulmonary venous return under the age of 5 months using normothermic cardiopulmonary bypass. These reports are encouraging; however, until the time that such results of early surgical treatment are obtainable in all centres, balloon atrial septostomy can offer a safe and effective form of palliative treatment in most of these patients with a greater overall survival.

The foramen ovale has been reported to be a site of obstruction in patients with total anomalous pulmonary venous return (Burchell, 1956; Burroughs and Edwards, 1960; Serrato et al., 1968; Miller et al., 1967). Bonham-Carter, Capriles, and Noe (1969) reported that all their patients surviving beyond the first year of life had a secundum atrial septal defect. Miller et al. (1967) and Serrato et al. (1968) performed balloon atrial septostomy in ro infants who were in congestive heart failure and who had no extracardiac pulmonary venous obstruction, obtaining clinical and haemodynamic improvement in most of the patients. In a previous study (El-Said et al., 1972), it has been documented that patients with total anomalous pulmonary venous return and small foramen ovale may have no pressure gradient across the atrial septum. The absence of pressure gradient in the presence of a small atrial communication is explained by the greater compliance of the right atrium than the left atrium (Cournand et al., 1947) which allows a large volume to develop within the right atrium without concomitant high pressure.

In total anomalous pulmonary venous return, pulmonary as well as systemic venous blood returns to the right atrium. The preferential flow is to the right ventricle. Even minor obstruction between the right and left atrium will potentiate this type of preferential flow. In patients with total anomalous pulmonary venous return and inadequate atrial communication, the majority of the circulating blood is sequestered in the lungs, right heart, and large systemic veins. This preferential flow to the right heart often results in suprasystemic pulmonary artery pressure. Balloon septostomy results in an increased blood flow to the left atrium and systemic circulation together with a decrease in pulmonary blood flow producing remarkable clinical and haemodynamic improvement.

Balloon atrial septostomy in infants with total anomalous pulmonary venous return is technically more difficult than in other anomalies because of the relatively small left atrium and the difficulty in determining the actual catheter location in the absence of the usual landmarks of the pulmonary veins. Using a double lumen catheter and injecting a small amount of contrast medium is essential to identify unequivocally the catheter position before the balloon withdrawal. Balloon withdrawal across the atrial septum must be rapid, since the inflated balloon obstructs the entire systemic flow. Serrato et al. (I968) reported a patient with total anomalous pulmonary venous return who died due to rupture of the balloon. However, no complications related directly to the septostomy were encountered in our patients.

\section{Conclusions}

A small atrial communication does not necessarily produce an interatrial pressure gradient in patients with total anomalous pulmonary venous return. A balloon catheter should be used routinely in infants with total anomalous pulmonary venous return to measure the size of the atrial communication and to perform septostomy when resistance to balloon withdrawal is encountered. Though balloon atrial septostomy has been performed for relatively older patients, the procedure is most likely to be successful in infants under 3 months of age, in those with large pulmonary flow, and in patients without significant pulmonary venous obstruction. The haemodynamic improvement obtained by successful septostomy in any infant with total anomalous pulmonary venous return may allow delay of operation until a more optimal age.

\section{References}

Barratt-Boyes, B. G., Simpson, M., and Neutze, J. M. (1971). Intracardiac surgery in neonates and infants using deep hypothermia with surface cooling and limited cardiopulmonary bypass. Circulation, 43 and 44, Suppl. I, 25.

Bonham-Carter, R. E., Capriles, M., and Noe, Y. (I969). Total anomalous pulmonary venous drainage: a clinical and anatomical study of 75 children. British Heart fournal, 31, 45 .

Burchell, H. B., (1956). Total anomalous pulmonary venous drainage: clinical and physiologic patterns. Proceedings of the Staff Meetings of the Mayo Clinic, 31, 161.

Burroughs, J. T., and Edwards, J. E. (I960). Total anomalous pulmonary venous connection (review). American Heart fournal, 59, 913 
Cooley, D. A., Hallman, G. L., and Leachman, R. D. (1966). Total anomalous pulmonary venous drainage: correction with the use of cardiopulmonary bypass in 62 cases. Fournal of Thoracic and Cardiovascular Surgery, 51, 88.

Cournand, A., Motley, H. L., Himmelstein, A., Dresdale, D., and Baldwin, J. (1947). Recording of blood pressure from the left auricle and the pulmonary veins in human subjects with interauricular septal defect. American fournal of Physiology, 150, 267.

Dillard, D. H., Mohri, H., and Merendino, K. A. (I97I). Correction of heart disease in infancy utilizing deep hypothermia and total circulatory arrest. Fournal of Thoracic and Cardiovascular Surgery, 61, 64.

El-Said, G., Mullins, C. E., and McNamara, D. G. (1972). Management of total anomalous pulmonary venous return. Circulation, 45, 1240.

Gathman, G. E., and Nadas, A. S. (1970). Total anomalous pulmonary venous connection: clinical and physiologic observations on 75 pediatric patients. Circulation, 42, 143.

Gersony, W. M., Bowman, F. O., Jr., Steeg, C. N., Hayes, C. J., Jesse, M. J., and Malm, J. R. (I97I). Management of total anomalous pulmonary venous drainage in early infancy. Circulation, 43 and 44, Suppl. I, 19.

Leachman, R. D., Cooley, D. A., Hallman, G. L., Simpson, J. W., and Dear, W. E. (1969). Total anomalous pulmon- ary venous return: correlation of hemodynamic observations and surgical mortality in 58 cases. Annals of Thoracic Surgery, 7, 5 .

Miller, W. W., Rashkind, W. J., Miller, R. A., Hastreiter, A. R., Green, E. W., Golinko, R. J., and Young, D. (1967). Total anomalous pulmonary venous return: effective palliation of critically ill infants by balloon atrial septotomy (abstract). Circulation, 35 and 36, Suppl. II, I89.

Mustard, W. T., Keith, J. D., and Trusler, G. A. (I962). Two-stage correction for total anomalous pulmonary venous drainage in childhood. Fournal of Thoracic and Cardiovascular Surgery, 44, 477.

Rashkind, W. J., and Miller, W. W. (1966). Creation of an atrial septal defect without thoracotomy: palliative approach to complete transposition of the great arteries. Fournal of the American Medical Association, 196, 991.

Serrato, M., Bucheleres, H. G., Bicoff, P., Miller, R. A., and Hastreiter, A. R. (1968). Palliative balloon atrial septostomy for total anomalous pulmonary venous connection in infancy. Fournal of Pediatrics, 73, 734.

Requests for reprints to Dr. Charles E. Mullins, Texas Children's Hospital, P.O. Box 20269, Houston, Texas 77025, U.S.A. 